УДК $338.012+330.44$

DOI 10.18101/2304-4446-2020-4-44-51

\title{
АНАЛИЗ ОТРАСЛЕВОЙ СТРУКТУРЫ ЭКОНОМИКИ МОНГОЛИИ С ИСПОЛЬЗОВАНИЕМ ТАБЛИЦ «ЗАТРАТЫ-ВЫПУСК»
}

\author{
(C) Дондоков Зорикто Бато-Дугарович \\ доктор экономических наук, профессор, \\ Бурятский научный центр СО РАН \\ Россия, 670047, г. Улан-Удэ, ул. Сахьяновой, 8 \\ Бурятский государственный университет имени Доржи Банзарова \\ Россия, 670000, г. Улан-Удэ, ул. Смолина, 24а \\ dzorikto@mail.ru

\section{(C) Базаров Александр Борисович} \\ обучающийся, \\ Бурятский государственный университет имени Доржи Банзарова \\ Россия, 670000, г. Улан-Удэ, ул. Смолина, 24a \\ sasha.bazarov.97@bk.ru
}

Аннотация. В статье проведен анализ основных показателей социальноэкономического развития и отраслевой структуры экономики Монголии с использованием таблиц «затраты-выпуск» за 2010 и 2018 гг. Дано описание порядка разработки и представления отчетов по национальным счетам страны. Исследована структура валового выпуска Монголии по видам экономической деятельности, выявлено существенное увеличение удельного веса отраслей обрабатывающей промышленности, строительства, финансовой деятельности. На основе данных по первому квадранту межотраслевого баланса Монголии проведен анализ итоговых показателей промежуточного потребления и промежуточного спроса по отраслям экономики. Проанализированы изменения структуры конечного спроса и валовой добавленной стоимости по видам экономической деятельности с использованием информации по второму и третьему квадрантам симметричной таблицы «затраты-выпуск». Выявлено увеличение доли обрабатывающих производств и строительства в отраслевой структуре экономики Монголии при снижении удельного веса видов экономической деятельности «оптовая и розничная торговля», «транспортировка и хранение», «сельское хозяйство, лесное хозяйство и рыболовство».

Ключевые слова: Монголия; экономика; система национальных счетов; вид экономической деятельности; межотраслевой баланс; отраслевая структура; валовой выпуск; промежуточное потребление; промежуточный спрос; валовая добавленная стоимость; конечный спрос.

\section{Для цитирования}

Дондоков 3. Б.-Д., Базаров А. Б. Анализ отраслевой структуры экономики Монголии с использованием таблиц «затраты-выпуск» // Вестник Бурятского государственного университета. Экономика и менеджмент. 2020. № 4. С. 44-51. 
3. Б.-Д. Дондоков, А. Б. Базаров. Анализ отраслевой структуры экономики Монголии с использованием таблиц «затраты-выпуск»

За последние десятилетия Монголия превратилась в динамично развивающуюся страну, увеличив в три раза свой ВВП на душу населения с 1991 г. ${ }^{1}$ В долгосрочной перспективе у страны есть достаточные предпосылки устойчивого развития экономики, включая наличие значительных сельскохозяйственных и минеральных ресурсов и рост человеческого потенциала.

В условиях специфики географического положения для экономики Монголии важное значение имеет внешнеэкономическое сотрудничество с двумя соседними державами - Россией и Китаем [1], включая реализацию китайского проекта «Экономический пояс Шелкового пути» и проектов программы «Экономический коридор Китай — Монголия — Россия» [2; 3; 4].

Бурное развитие Монголии привело к существенным изменениям в отраслевой структуре экономики страны к 2010 г. [5; 6]. Наибольшее развитие получили горнодобывающая промышленность и сфера услуг [7]. Активно развивается транспортная система Монголии [8]. В настоящее время происходит формирование новых отраслей экономики, основанных на современных знаниях и технологиях. Переход на предпринимателей на онлайн-деятельность создает предпосылки появления цифровой экономики [9].

В целом в последние годы экономика Монголии развивается достаточно высокими темпами. ВВП страны с 2010 по 2018 г. увеличился в 3,32 раза (табл. 1). Среднегодовая численность занятых в экономике за эти годы возросла на $21,2 \%$ при росте численности населения на 17,2 \%. Незначительно снизился уровень безработицы. Заметный прирост внешнеторгового оборота в основном обусловлен увеличением экспортной составляющей. В структуре капиталовложений Монголии следует отметить высокую степень иностранного участия, вызванную активным инвестированием зарубежные компании в горнодобывающую отрасль.

Таблица 1

Основные показатели социально-экономического положения Монголии в 2010 и в 2018 гг.*

\begin{tabular}{|l|c|c|}
\hline \multicolumn{1}{|c|}{ Показатель } & $\mathbf{2 0 1 0}$ г. & $\mathbf{2 0 1 8}$ г. \\
\hline $\begin{array}{l}\text { ВВП, млн тугриков, в том числе } \\
\text { по секторам: }\end{array}$ & 9756588,4 & 32411224,1 \\
\hline первичный & 3246855,8 & 11216741,4 \\
\hline вторичный & 1136468,2 & 4937015,5 \\
\hline третичный & 5373264,3 & 16257467,0 \\
\hline Численность населения, млн чел. & 2,761 & 3,238 \\
\hline $\begin{array}{l}\text { Среднегодовая численность занятых } \\
\text { в экономике, млн чел. }\end{array}$ & 1,034 & 1,253 \\
\hline Уровень безработицы, \% & 6,55 & 6,25 \\
\hline $\begin{array}{l}\text { Инвестиции в основной капитал, млн тугр., } \\
\text { в т. ч.: }\end{array}$ & 3845809,1 & 12515516,3 \\
\hline внутренние инвестиции & 1403324,0 & 5124750,2 \\
\hline иностранные инвестиции & 2442485,1 & 7390766,0 \\
\hline доля внутренних инвестиций, \% & 36,49 & 40,95 \\
\hline
\end{tabular}

1 The World Bank in Mongolia [Электронный pecypc]. URL: https://www.worldbank.org/en/country/mongolia/overview (дата обращения: 09.08.2020). 


\begin{tabular}{|l|c|c|}
\hline доля иностранных инвестиций, \% & 63,51 & 59,05 \\
\hline $\begin{array}{l}\text { Внешнеторговый оборот млн долл. США, } \\
\text { в т. ч.: }\end{array}$ & 6108,6 & 12886,8 \\
\hline экспорт & 2908,5 & 7011,8 \\
\hline импорт & 3200,1 & 5875 \\
\hline
\end{tabular}

* Составлено по: Монгол улсын статистикийн эмхэтгэл - 2011 // Монгол улсын ундэсний статистикийн хороо. Улаанбаатар, 2011. 487 с.; Монгол улсын статистикийн эмхэтгэл - 2019 // Монгол улсын ундэсний статистикийн хороо. Улаанбаатар, 2019. 589 с.

Отраслевая структура ВВП Монголии характеризуется преобладанием третичного сектора: сфера услуг обеспечивает 55,07\% от ВВП в 2010 г. против $50,16 \%$ в 2018 г. За исследуемый период произошло увеличение доли первичного сектора на $1,33 \%$ и вторичного на $3,58 \%$.

Значительное изменение структуры экономики Монголии определяет необходимость детального отраслевого анализа. Универсальным инструментом проведения таких исследований является метод межотраслевого анализа, разработанный выдающимся американским ученым российского происхождения В. В. Леонтьевым [10].

Информационную основу межотраслевого баланса (МОБ) составляют таблицы «затраты-выпуск» (ТЗВ), в которых отражается процессы производства и распределения продукции по видам экономической деятельности (ВЭД) [11]. Указанные таблицы являются важным элементом системы национальных счетов ${ }^{1}$.

В Монголии национальные счета составляются и распространяются Национальным статистическим управлением Монголии. Годовые и квартальные отчеты по национальным счетам составляются и распространяются через ежемесячные бюллетени и ежегодники Монголии. Данные о валовом внутреннем продукте и следующие за ним показатели также размещены на веб-сайте Национального статистического управления².

Система национальных счетов, используемая в Монголии, основана на методологической основе Системы национальных счетов 2008 (СНС, 2008). С 1995 г. оценки ВВП рассчитывались с использованием показателей СНС 1993 г. До 1995 г. в Монголии использовалась концепция национального экономического баланса (NEB). C 1995 по 2010 г. экономическая деятельность классифицировалась в соответствии с Международной стандартной отраслевой классификацией всех видов экономической деятельности (ISIC Rev.3) $)^{3}$. Симметричные ТЗВ были опубликованы за 1966, 1970, 1977, 1983, 1987, 2000 и 2005 годы. С 2010 г. таблицы ресурсов и использования публикуются ежегодно.

\footnotetext{
${ }^{1}$ Система национальных счетов 2008. Нью-Йорк: Европейская комиссия, Международный валютный фонд, Организация экономического сотрудничества и развития, Организация Объединенных Наций и Всемирный банк. 2012. 764 с.

${ }^{2}$ Статистикийн мэдээллийн нэгдсэн сан [Электронный ресурc]. URL: http://1212.mn/ (дата обращения: 11.08.2020).

${ }^{3}$ International Standard Industrial Classification of All Economic Activities [Электронный pecypc]. URL: https://unstats.un.org/unsd/statcom/doc02/isic.pdf (дата обращения: 12.08.2020).
} 
3. Б.-Д. Дондоков, А. Б. Базаров. Анализ отраслевой структуры экономики Монголии с использованием таблиц «затраты-выпуск»

В ТЗВ Монголии с 2010 по 2018 г. учтены 20 отраслей экономики в миллионах тугриков. Во втором квадранте межотраслевого баланса отражены совокупное конечное потребление экономическими агентами, валовое накопление основного капитала и чистый экспорт. В третьем квадранте МОБ указаны данные по валовой добавленной стоимости, включающие оплату труда, другие налоги на продукцию, потребление основного капитала, операционный и смешанный доходы.

В таблице 2 показана структура валового выпуска Монголии по видам экономической деятельности по данным таблиц «затраты-выпуск» страны за 2010 и 2018 гг.

Таблица 2

Структура валового выпуска в Монголии за 2010 и 2018 гг., \%*

\begin{tabular}{|l|c|c|c|}
\hline \multicolumn{1}{|c|}{ Отрасль (ВэД) } & 2010 г. & 2018 г. & $\begin{array}{c}\text { Изменение } \\
\text { удельного веса } \\
\text { Вэд, \% }\end{array}$ \\
\hline $\begin{array}{l}\text { Сельское хозяйство, лесное хозяйство и ры- } \\
\text { боловство }\end{array}$ & 9,75 & 8,66 & $-1,09$ \\
\hline Добыча полезных ископаемых & 22,99 & 22,16 & $-0,83$ \\
\hline Обрабатывающие производства & 12,73 & 17,22 & 4,49 \\
\hline Электроэнергия, газ, пар и горячая вода & 3,55 & 3,85 & 0,29 \\
\hline Водоснабжение и канализация & 0,60 & 0,28 & $-0,32$ \\
\hline Строительство & 7,36 & 9,12 & 1,76 \\
\hline Оптовая и розничная торговля & 11,19 & 9,11 & $-2,08$ \\
\hline Транспортировка и хранение & 8,19 & 6,46 & $-1,73$ \\
\hline Гостиницы и рестораны & 1,31 & 1,54 & 0,22 \\
\hline Информация и связь & 2,71 & 2,37 & $-0,34$ \\
\hline Финансы и страхование & 2,07 & 3,50 & 1,44 \\
\hline Операции с недвижимым имуществом & 5,05 & 3,79 & $-1,26$ \\
\hline Научные исследования и разработки & 1,85 & 1,91 & 0,06 \\
\hline Административные и сопутствующие услуги & 0,99 & 1,39 & 0,40 \\
\hline $\begin{array}{l}\text { Государственное управление и обязательное } \\
\text { социальное обеспечение }\end{array}$ & 3,99 & 3,32 & $-0,67$ \\
\hline Образование & 3,15 & 2,66 & $-0,49$ \\
\hline $\begin{array}{l}\text { Здравоохранение и предоставление соци- } \\
\text { альных услуг }\end{array}$ & 1,71 & 1,73 & 0,02 \\
\hline Отдых и развлечения & 0,33 & 0,30 & $-0,03$ \\
\hline Прочие виды услуг & 0,48 & 0,64 & 0,15 \\
\hline
\end{tabular}

* Составлено по: Монгол улсын статистикийн эмхэтгэл - 2011 // Монгол улсын ундэсний статистикийн хороо. Улаанбаатар, 2011. 487 с.; Монгол улсын статистикийн эмхэтгэл - 2019 // Монгол улсын ундэсний статистикийн хороо. Улаанбаатар, 2019. 589 с.

В 2010 г. в Монголии значительная доля валового выпуска приходилась на добычу полезных ископаемых (22,99\%), обрабатывающие производства $(12,73 \%)$, торговлю $(11,19 \%)$, сельское хозяйство $(9,75 \%)$. К 2018 г. существенно увеличился удельный вес отраслей обрабатывающей промышленности, строительства, финансовой деятельности. За 2010-2018 гг. произошло снижение доли ВЭД «Оптовая и розничная торговля», «Транспортировка и хранение», «Операции с недвижимым имуществом», «Сельское хозяйство, лесное хозяйство и рыболовство». 
В таблице 3 отражены данные по результирующим векторам первого квадранта межотраслевого баланса Монголии за 2010 и 2018 гг.

Таблица 3

Структура промежуточного потребления (ПП) и промежуточного спроса (ПС) по отраслям в экономике Монголии в 2010 и 2018 г., \%*

\begin{tabular}{|l|c|c|c|c|}
\hline \multicolumn{1}{|c|}{ Отрасль } & ПП, 2010 г. & ПП, 2018 г. & ПС, 2010 г. & ПС, 2018 \\
\hline $\begin{array}{l}\text { Сельское хозяйство, лесное } \\
\text { хозяйство и рыболовство }\end{array}$ & 6,75 & 5,73 & 11,37 & 8,09 \\
\hline Добыча полезных ископаемых & 21,62 & 17,59 & 5,03 & 4,44 \\
\hline $\begin{array}{l}\text { Обрабатывающие производ- } \\
\text { ства }\end{array}$ & 17,73 & 23,51 & 34,85 & 34,24 \\
\hline $\begin{array}{l}\text { Электроэнергия, газ, пар и } \\
\text { горячая вода }\end{array}$ & 5,35 & 5,22 & 6,90 & 8,28 \\
\hline $\begin{array}{l}\text { Водоснабжение и канализа- } \\
\text { ция }\end{array}$ & 0,85 & 0,66 & 1,47 & 0,32 \\
\hline Строительство & 11,49 & 13,41 & 4,93 & 5,99 \\
\hline Оптовая и розничная торговля & 8,87 & 7,91 & 8,16 & 9,30 \\
\hline Транспортировка и хранение & 8,35 & 7,43 & 9,15 & 8,30 \\
\hline Гостиницы и рестораны & 1,96 & 1,83 & 1,25 & 1,28 \\
\hline Информация и связь & 2,51 & 2,77 & 3,56 & 3,79 \\
\hline Финансы и страхование & 1,45 & 1,84 & 3,70 & 6,12 \\
\hline $\begin{array}{l}\text { Операции с недвижимым } \\
\text { имуществом }\end{array}$ & 2,42 & 1,57 & 2,33 & 1,82 \\
\hline $\begin{array}{l}\text { Научные исследования и раз- } \\
\text { работки }\end{array}$ & 2,17 & 2,31 & 3,38 & 4,56 \\
\hline $\begin{array}{l}\text { Административные и сопут- } \\
\text { ствующие услуги }\end{array}$ & 1,05 & 1,82 & 1,47 & 1,71 \\
\hline $\begin{array}{l}\text { Государственное управление } \\
\text { и обязательное социальное } \\
\text { обеспечение }\end{array}$ & 3,16 & 2,57 & 1,40 & 0,57 \\
\hline Образование & 0,29 & 1,35 & 0,47 & 0,24 \\
\hline $\begin{array}{l}\text { Здравоохранение и предо- } \\
\text { ставление социальных услуг }\end{array}$ & 0,73 & 0,27 & 0,40 \\
\hline Отдых и развлечения & 2,02 & 0,12 & 0,14 \\
\hline Прочие виды услуг & 1,52 & 0,42 \\
\hline
\end{tabular}

* Составлено по: Монгол улсын статистикийн эмхэтгэл - 2011 // Монгол улсын ундэсний статистикийн хороо. Улаанбаатар, 2011. 487 с.; Монгол улсын статистикийн эмхэтгэл - 2019 // Монгол улсын ундэсний статистикийн хороо. Улаанбаатар, 2019. 589 с.

В 2010 г. значительная часть ПП приходилась на добычу полезных ископаемых (21,62\%), обрабатывающую промышленность $(17,73 \%)$, строительство (11,49\%). Почти половина ПС Монголии была распределена по двум отраслям экономики - обрабатывающим производствам $(34,85 \%)$ и сельскому хозяйству $(11,37 \%)$.

В 2018 г. произошла смена «лидера» по ПП: на долю обрабатывающих производств пришлось 23,51\% (прирост на 5,78 процентных пункта). Удельный вес ВЭД «добыча полезных ископаемых» снизилась до 17,59\%. Значительно (на 3,28 
3. Б.-Д. Дондоков, А. Б. Базаров. Анализ отраслевой структуры экономики Монголии с использованием таблиц «затраты-выпуск»

процентных пункта) снизилась доля сельского хозяйства в промежуточном спросе. Удельный вес ВЭД «обрабатывающая промышленность» уменьшился незначительно и составил $34,24 \%$ суммарного ПС.

Отраслевая структура конечного спроса (КС) по второму квадранту МОБ и валовой добавленной стоимости (ВДС) по третьему квадранту МОБ показана в табл. 4. Структура валовой добавленной стоимости Монголии характеризуется высоким удельным весом ВЭД «добыча полезных ископаемых», «оптовая и розничная торговля» и «сельское хозяйство». На их долю приходится около половины ВДС страны. За период с 2010 по 2018 г. произошло значительное увеличение (более чем на треть) удельного веса вида экономической деятельности «обрабатывающие производства». Напротив, существенно снизилась доля ВЭД «транспортировка и хранение», а также «оптовая и розничная торговля».

Таблица 4

Отраслевая структура валовой добавленной стоимости (ВДС) и конечного спроса (КС) в экономике Монголии в 2010 и 2018 гг., \%*

\begin{tabular}{|c|c|c|c|c|}
\hline Отрасль (ВЭД) & ВДС, 2010 г. & ВДС, 2018 г. & КC, 2010 г. & KC, 2018 \\
\hline $\begin{array}{l}\text { Сельское хозяйство, лесное } \\
\text { хозяйство и рыболовство }\end{array}$ & 12,62 & 11,53 & 8,18 & 9,22 \\
\hline Добыча полезных ископаемых & 24,31 & 26,67 & 40,23 & 39,62 \\
\hline Обрабатывающие производства & 7,93 & 10,97 & $-8,50$ & 0,46 \\
\hline $\begin{array}{l}\text { Электроэнергия, газ, пар и } \\
\text { горячая вода }\end{array}$ & 1,83 & 1,98 & 0,34 & $-0,51$ \\
\hline Водоснабжение и канализация & 0,36 & 0,47 & $-0,23$ & 0,23 \\
\hline Строительство & 3,40 & 4,89 & 9,70 & 12,20 \\
\hline Оптовая и розничная торговля & 13,42 & 10,30 & 14,10 & 8,92 \\
\hline Транспортировка и хранение & 8,03 & 5,50 & 7,26 & 4,64 \\
\hline Гостиницы и рестораны & 0,69 & 1,24 & 1,37 & 1,79 \\
\hline Информация и связь & 2,89 & 1,97 & 1,88 & 0,97 \\
\hline Финансы и страхование & 2,66 & 5,14 & 0,50 & 0,93 \\
\hline $\begin{array}{l}\text { Операции с недвижимым } \\
\text { имуществом }\end{array}$ & 7,58 & 5,98 & 7,66 & 5,73 \\
\hline $\begin{array}{l}\text { Научные исследования и раз- } \\
\text { работки }\end{array}$ & 1,54 & 1,52 & 0,38 & $-0,69$ \\
\hline $\begin{array}{l}\text { Административные и сопут- } \\
\text { ствующие услуги }\end{array}$ & 0,93 & 0,96 & 0,53 & 1,07 \\
\hline $\begin{array}{l}\text { Государственное управление } \\
\text { и обязательное социальное } \\
\text { обеспечение }\end{array}$ & 4,79 & 4,07 & 6,47 & 6,04 \\
\hline Образование & 4,24 & 3,95 & 5,72 & 5,04 \\
\hline $\begin{array}{l}\text { Здравоохранение и предо- } \\
\text { ставление социальных услуг }\end{array}$ & 1,90 & 1,94 & 3,09 & 3,05 \\
\hline Отдых и развлечения & 0,36 & 0,38 & 0,53 & 0,46 \\
\hline Прочие виды услуг & 0,51 & 0,54 & 0,77 & 0,85 \\
\hline
\end{tabular}

* Составлено по: Монгол улсын статистикийн эмхэтгэл - 2011 // Монгол улсын ундэсний статистикийн хороо. Улаанбаатар, 2011. 487 с.; Монгол улсын статистикийн эмхэтгэл - 2019 // Монгол улсын ундэсний статистикийн хороо. Улаанбаатар, 2019. 589 с. 
В структуре конечного спроса Монголии значительно выше удельный вес добывающей промышленности (около 40\%), также около 10\% обладают сельское хозяйство, строительство. Следует отметить отрицательные значения КС по ВЭД «обрабатывающие производства» и «водоснабжение и канализация» в 2010 г., а также «электроэнергия, газ, пар и горячая вода» и «научные исследования и разработки» в 2018 г. Данное явление обусловлено превышением значения импорта в данных отраслях экономики над всеми остальными статьями конечного спроса и свидетельствует о высокой зависимости указанных ВЭД Монголии от завозимой продукции. За прошедшие 8 лет обрабатывающие производства вышли из отрицательного сальдо по КС, значительно возросла доля строительства. Вместе с тем произошло значительное падение удельного веса ВЭД «оптовая и розничная торговля» и «транспортировка и хранение».

В целом за период с 2010 по 2018 г. повысилась значимость ВЭД «обрабатывающие производства»: доля этой отрасли в экономике Монголии увеличилась в валовом выпуске, промежуточном потреблении, валовой добавленной стоимости, конечном спросе. Произошло увеличение доли строительства по всем анализируемым показателям. В основном отрицательной динамикой за прошедший период характеризовались ВЭД «оптовая и розничная торговля» и «транспортировка и хранение», «сельское хозяйство, лесное хозяйство и рыболовство».

\section{Литература}

1. Миронова М. Н., Потапенко М. В. Современные тенденции экономического сотрудничества Монголии с Китаем и Россией // Известия Тульского государственного университета. Экономические и юридические науки. 2016. № 3-1. С. 11-25.

2. Грайворонский В. В. Китайский мегапроект «Экономический пояс Шелкового пути»: место и роль Монголии // Восточная аналитика. 2018. № 3. С. 49-59.

3. Борисов Г. О., Дондоков 3. Б.-Д., Намжилова В. О. Экономический коридор Китай - Монголия - Россия: режим ожидания // ЭКО. 2017. № 5. С. 98-106.

4. Суходолов Я. А., Даваасурэн А., Манжигеев А. Ф. Современная специфика и перспективы развития внешнеторгового сотрудничества России с Монголией // Известия Байкальского государственного университета. 2018. Т. 28, № 4. С. 632-639.

5. Гомбоев А. Б., Базаров В. Б. Динамика макроэкономических показателей и внешнеэкономические связи Монголии // Вестник Бурятского научного центра Сибирского отделения Российской академии наук. 2014. № 4(16). С. 132-151.

6. Дугер Г. Экономика Монголии: структурный анализ // Международный научноисследовательский журнал. 2015. № 3(34), ч. 3. С. 15-18.

7. Потаев В. С. О некоторых проблемах и путях социально-экономического развития Монголии // Вестник Бурятского государственного университета. 2015. № 2-1. С. 88-92.

8. Булатова Н. Н., Тихонова П. В. Международное сотрудничество в транспортной сфере в условиях формирования экономического коридора «Россия - Монголия - Китай» // Вестник ВСГУТУ. 2018. № 2(69). С. 101-108.

9. Кутовой В. М., Дулгуун А. Цифровая экономика Монголии в контексте развития мировой цифровой экономики. Вестник РГГУ. Сер. Экономика. Управление. Право. 2019. № 4, ч. 2. С. 209-219.

10. Леонтьев В. В. Межотраслевая экономика: пер. с англ. М.: Экономика, 1997. 471 с.

11. Miller R. E., Blair P. D. Input-Output Analysis: Foundations and Extensions. $2^{\text {nd }}$ ed. N. Y.: Cambridge University Press, 2009. 749 p. 


\section{ANALYSIS OF THE SECTORAL STRUCTURE \\ OF MONGOLIA'S ECONOMY BY MEANS OF INPUT-OUTPUT TABLES}

Zorikto B.-D. Dondokov

Dr. Sci. (Econ.), Prof.,

Buryat Scientific Center SB RAS

8 Sakhyanovoy St., Ulan-Ude 670047, Russia

Dorzhi Banzarov Buryat State University

24a Smolina St., Ulan-Ude 670000, Russia

dzorikto@mail.ru

Aleksandr B. Bazarov

Student,

Dorzhi Banzarov Buryat State University

24a Smolina St., Ulan-Ude 670000, Russia

sasha.bazarov.97@bk.ru

Abstract. The article analyzes the key social indicators and sectoral structure of Mongolia's economy through the use of input-output tables for 2010 and 2018. It is described the procedure for the development and submission of reports on national accounts. In the article we have investigated the structure of Mongolia's gross output by types of economic activity, and revealed a significant increase in the proportion of manufacturing, construction, and financial activities. Based on the data on the $1^{\text {st }}$ quadrant of Mongolia's inputoutput balance we have carried out an analysis of the final indicators of intermediate consumption and intermediate demand by economy sectors. Information on the $2^{\text {nd }}$ and $3^{\text {rd }}$ quadrants of the symmetric input-output table allowed us to analyze the changes in the structure of final demand and gross value added by type of economic activity. As a result, it has been revealed an increase in the share of manufacturing and construction in the sectoral structure of Mongolia's economy with a decrease in the share of such economic activities as "wholesale and retail trade" and "transportation and storage", "agriculture, forestry and fishing".

Keywords: Mongolia; economy; system of national accounts; type of economic activity; input-output balance; sectoral structure; gross output; intermediate consumption; intermediate demand; gross value added; final demand.

Статья поступила в редакцию 14.10.2020; одобрена после рецензирования 30.10.2020; принята к публикации 30.10.2020. 